\title{
Acute myocardial infarction and arterial embolectomy
}

\author{
Mendel Stavorovsky \\ M.D., F.I.C.S., F.I.C.A.
}
Alberto IELLIN
M.D.

BARUCH MORAG
M.D.

DAN LICHTENSTEIN

M.D.

Department of General and Vascular Surgery, Municipal Governmental Medical Center Tel-Aviv, Ichilov Hospital, Tel-Aviv, Israel

\begin{abstract}
Summary
Emboli of a main artery cause serious complications in patients suffering from acute myocardial infarction, in whom the surgical risk is high. In order to save the limb, embolectomy is indicated and should be considered.

Early diagnosis and prompt surgical intervention with the use of the Fogarty catheter simplify the embolectomy procedure and enable restoration of circulation to the ischaemic limb.

Thirty-two embolectomies were performed in twenty-eight patients suffering from acute myocardial infarction. Patients with cardiac compensation survived the surgery and recovered. However $50 \%$ of the patients in whom acute myocardial infarction was accompanied with congestive heart failure and arrhythmias died. The cause of death was the underlying disease. Considering the severity of the acute myocardial infarction this group of patients represents the expected mortality.
\end{abstract}

\section{Introduction}

Until recently, sudden occlusion of a main artery in patients suffering from acute myocardial infarction was a dangerous complication fatal in a high percentage of cases.

Improvement in the technique of removal of emboli by the use of the Fogarty catheter, in conjunction with intensive cardiac care and monitoring, enables embolectomy to be performed on patients with acute myocardial infarction accompanied by arrhythmias and even congestive heart failure.

In spite of atherosclerotic changes in the arterial tree of the majority of elderly patients suffering from acute myocardial infarction and embolic complications, it is possible today, through early diagnosis, heparinization and prompt surgery, to restore good circulation to the ischaemic limb and to save it.

Requests for reprints: M. Stavorovsky, M.D., Head of Surgical Department 'C', Ichilov Hospital, Tel-Aviv, Israel.
The mortality rate which is still high, is attributed to the underlying disease, from which $7 \%$ of the patients who survived the first week following the onset of their myocardial infarction, die withiro 30 days.

The following study of thirty-two embolectomiesperformed on twenty-eight patients admitted fo acute myocardial infarction, illustrates the import? ance and advisability of this surgical procedure or this group of patients.

\section{Clinical material}

During the period 1967-76, the Medical Cerifire of Tel-Aviv treated 9765 patients suffering from acute myocardial infarction. One thousand seven $\bar{\partial}$ hundred and two of these died within the first weel ${ }_{2}$ of being admitted to hospital (Table 1). Among the 8063 patients who survived the first week of the illness, thirty-four had arterial emboli of the extre $\frac{0}{3}$ mities $(0.4 \%)$. Six of these patients, in whom occlusion occurred in the distal arteries, were successfully treated by conservative medical manage ment. Thirty-two embolectomies were performed on the remaining twenty-eight patients.

During the same period (1967-76) a total op 132 arterial embolectomies were performed on 114 patients. The twenty-eight patients suffering from acute myocardial infarction represent $24.5 \%$ of the total group. In sixteen cases, arterial emboli occurred in the second week, and in twelve cases? during the third week following onset of acute్

TABLE 1. Mortality among 9765 patients with acute myocardial infarction (AMI)

\begin{tabular}{lcc}
\hline $\begin{array}{l}\text { Days following } \\
\text { onset of AMI }\end{array}$ & $\begin{array}{c}\text { No. of } \\
\text { patient } \\
\text { deaths }\end{array}$ & $\begin{array}{c}\text { Patient } \\
\text { deaths } \\
(\%)\end{array}$ \\
\hline $1-7$ & 1702 & $17 \cdot 43$ \\
$7-30$ & 730 & $7 \cdot 47$ \\
Total & 2432 & 24.90 \\
\hline
\end{tabular}


myocardial infarction. A number of the patients suffered from additional diseases (Table 2). Upon admission to hospital, seven patients showed a mild decrease in blood pressure, while a violent decrease was found in two patients $(60-70 \mathrm{mmHg})$. Arrhythmias were noted in twenty-three patients and congestive heart failure in twelve of the group. There were ten female and eighteen male patients. Their ages ranged from 60-92 years (Table 3). Almost 50\% of the patients were in the 70-79 year age group. Of the remaining eighty-six patients with other embolic aetiology, $32 \%$ were under 60 years of age.

TABLE 2. Incidence of associated significant illnesses to the acute myocardial infarction in the present series

\begin{tabular}{lc}
\hline Disease & $\begin{array}{c}\text { No. of } \\
\text { patients }\end{array}$ \\
\hline Hypertension* & 15 \\
Old myocardial infarction & 3 \\
Pulmonary emphysema & 14 \\
Diabetes mellitus & 6 \\
Claudication-distance & 6 \\
\hline
\end{tabular}

* Old hemiparesis, 4 patients.

TABLE 3. Age distribution

\begin{tabular}{lc}
$\begin{array}{c}\text { Age } \\
\text { (years) }\end{array}$ & $\begin{array}{c}\text { No. of } \\
\text { patients }\end{array}$ \\
\hline $60-69$ & 12 \\
$70-79$ & 14 \\
$80-92$ & 2 \\
Total & 28 \\
\hline
\end{tabular}

Early diagnosis of arterial emboli was easily made among the group of thirty-four patients. The presence of acute myocardial infarction which was in the majority of cases accompanied by arrhythmia, severe sudden pain, coldness and pallor of the limb and absence of distal pulses below the emboli, verified the diagnosis. In four cases, it was necessary to perform a peripheral arteriography (Fig. 1) in order to rule out the presence of acute thrombosis of the artery. In two of these cases, the reason was a past history of intermittent claudication, and in the other two cases, decrease in blood pressure upon admission.

Within 4-8 hours following appearance of the emboli thirty-two embolectomies were performed in twenty-eight patients. In three patients, on the alternate limb, and in one patient a repeated embolectomy was successfully done following a recurrent episode. General anaesthesia was used in four cases; epidural in sixteen, and local anaesthesia on nine patients. In twenty-three cases the femoral artery was blocked by emboli (Table 4).

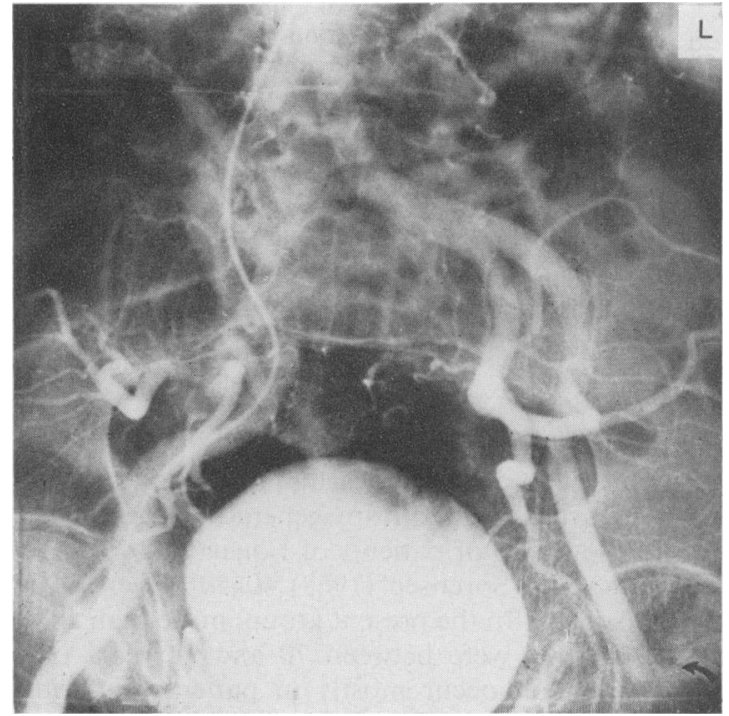

FIG. 1. Peripheral arteriography: shows tortuosity of the great vessels with clear-cut occlusion of the left external iliac artery (arrow) with signs of collateral circulation above. The clear-cut occlusion indicates an acute embolic block.

In all thirty-one embolectomies the Fogarty catheter was used and surgical procedure was technically simple. With the exception of one case, secondary thrombi were not found and flushing of the artery was not necessary. Good circulation was restored in thirty-one cases of embolectomy. In the remaining patient who suffered from ischaemia of the limb previous to the acute myocardial infarction, no improvement in circulation was noted. Peripheral pulses were felt in thirteen patients after surgery. Among the remaining fifteen, the distal pulses were absent in the alternate limb of nine patients upon admission.

Six of the twenty-eight patients died, a mortality rate of $21.4 \%$. The cause of death was directly related to the severity of the myocardial infarction (Table 5). In the group of 86 patients with emboli of other aetiology, sixteen died, representing a mortality rate of $18.6 \%$. One patient aged 92 died $4 \mathrm{hr}$ after undergoing the embolectomy with restored circulation in the limb. In one case it was not possible to restore circulation because of old obliteration of the superficial femoral artery and presence of secondary thrombi in the deep femoral artery which developed within 7 hours of the emboli. Amputation was performed after 7 days and the patient died 4 days later (Table 5, Case no. 6). The remaining four patients survived the embolectomy procedure, but died within 10-17 days following surgery because of the severity of their heart failures. 
TABLE 4. Distribution of emboli according to location

\begin{tabular}{lc}
\hline Location of emboli & Incidence \\
\hline Bifurcation of aorta & 3 \\
Iliac artery & 4 \\
Common femoral artery & 15 \\
Superficial femoral artery & 8 \\
Axillary artery & 2 \\
Brachial artery & $3^{*}$ \\
Below popliteal artery & $3^{*}$ \\
\hline
\end{tabular}

* Conservative treatment.

\section{Discussion}

Patients with acute myocardial infarction complicated by arterial emboli are generally of advanced age. In the group of patients of Fogarty (1973), and of Nielsen and Sorensen (1968) $40-50 \%$ were over 70 years of age. In the present group, more than $50 \%$ of the patients were between 70 and 92 years old. Arterial emboli occur mostly in patients suffering from severe acute myocardial infarction (Nielsen and Sorensen, 1968). Peripheral arterial emboli occur in less than $1 \%$ of cases with acute myocardial infarction (Nielsen and Sorensen, 1968; Thompson et $a l ., 1970 \mathrm{~b})$. In the present group the incidence was $0.4 \%$. According to Fogarty (1973), Nielsen and Sorensen (1968), Stallone et al. (1969) and Thompson et al. (1970a), patients with acute myocardial infarction comprised $15 \cdot 6-19 \%$ of total embolectomy cases (Table 6). Embolic occlusion of the arteries below the brachial artery and below the popliteal artery rarely result in gangrene, therefore conservative treatment is possible (Stavorovsky, 1971).

Surgical risks are higher in patients suffering from acute myccardial infarction, particularly when accompanied by congestive heart failure and arrhythmia. Generally in such cases elective surgery
TABLE 6. Cases of embolectomy reported by different authors

\begin{tabular}{|c|c|c|c|}
\hline Author & $\begin{array}{c}\text { Total } \\
\text { embolectomy } \\
\text { patients }\end{array}$ & $\begin{array}{c}\text { Acute } \\
\text { myocardial } \\
\text { infarction } \\
\text { embolectomy } \\
\text { patients }\end{array}$ & $(\%)$ \\
\hline Fogarty (1973) & 300 & 50 & \\
\hline $\begin{array}{l}\text { Nielsen and Sorensen } \\
\text { (1968) }\end{array}$ & 140 & 22 & \\
\hline Thompson (1970a) & 163 & 31 & $19 \cdot 0$ \\
\hline Stallone (1969) & 16 & 3 & $19 \cdot 0$ \\
\hline Present series & 114 & 28 & $24 \cdot 5$ \\
\hline
\end{tabular}

is contraindicated. However, in order to save limb and possibly the patient's life, embolectomy 2 . must be considered. Conservative treatment in casesir of emboli of a main artery does not suffice. The occurrence of severe pain and acidosis resulting from resorption of toxins from the ischaemic organ is interferes with the treatment of the heart diseasedo by infarct, and endangers the patient's life.

In most cases gangrene can develop despitec conservative treatment, and amputation has to bes performed after 8-10 days. This surgical procedure is more difficult and drastic than the embolectomy, and sometimes causes mental and emotional stresso in the patient, and can even precipitate his dea Therefore embolectomy in patients suffering fre acute myocardial infarction must be considered in every case of embolic occlusion of a main artery (Stavorovsky, 1971). The cardiologist who hesitateso to refer to surgery the patient with myocardiafo infarction in congestion and arrhythmia must then provide conservative treatment. This approach leadsô to delayed surgery which is more complicated and of longer duration. The surgeon must remove second ary thrombi which have since developed in the distal

TABLE 5. Cause of death following embolectomy

\begin{tabular}{|c|c|c|c|c|c|c|}
\hline No. & $\begin{array}{c}\text { Age } \\
\text { (years) }\end{array}$ & $\begin{array}{c}\text { Previous } \\
\text { MI } \dagger\end{array}$ & $\begin{array}{l}\text { Diabetes } \\
\text { mellitus }\end{array}$ & $\begin{array}{c}\text { Time from MI } \dagger \\
\text { to embolectomy } \\
\text { (days) }\end{array}$ & $\begin{array}{c}\text { Time from operation } \\
\text { to death }\end{array}$ & Cause of death \\
\hline 1 & 92 & yes & yes & 10 & 4 hours & Sudden cardiac arrest \\
\hline 2 & 78 & no & no & 15 & 14 days & Congestive heart failure \\
\hline 3 & 72 & no & yes & 13 & 17 days & $\begin{array}{l}\text { Congestive heart failure, } \\
\text { ventricular fibrillation }\end{array}$ \\
\hline 4 & 60 & yes & no & 8 & 13 days & Congestive heart failure \\
\hline 5 & 66 & no & yes & 15 & 10 days & $\begin{array}{l}\text { Fresh myocardial } \\
\text { infarction }\end{array}$ \\
\hline 6 & 72 & no & no & 12 & 11 days* & $\begin{array}{l}\text { Congestive heart failure, } \\
\text { respiratory distress, } \\
\text { pulmonary infarction }\end{array}$ \\
\hline
\end{tabular}

\footnotetext{
* 4 days after amputation; $\dagger$ MI, myocardial infarction.
} 
arteries and veins. Flushing of the vein system is also sometimes necessary in order to prevent pulmonary emboli which might appear after the restoration of arterial circulation.

Factors which threaten the survival of the ischaemic limb, such as atheromatotic changes and even occlusions of the distal arteries, exist in this category of patients. Absence of distal pulses before onset of the myocardial infarction and history of claudication confirm this. Delay of surgery, therefore, decreases the number of successes.

Early diagnosis together with intensive cardiac treatment (if necessary) within a few hours following the onset of emboli, heparinization, and embolectomy performed under local anaesthesia by an experienced surgeon using a Fogarty catheter, simplifies the operation and widens the range of treatment choices in the majority of cases. This approach allows for a greater success rate, even in cases of acute myocardial infarction with congestive heart failure and arrhythmia which are complicated by emboli.

Prognosis depends on the condition of the heart (damaged) affected by infarct. Patients with acute myocardial infarction in a state of compensation without recurrence of emboli from the original source recovered. However, approximately $50 \%$ of patients with acute myocardial infarction accompanied by congestive heart failure and arrhythmia died (Gould and Migliorelli, 1967; Fogarty, 1973; Thompson et al., 1970a, b).

Similar results were noted in the present seriessix of twelve patients suffering from congestive heart failure and arrhythmia died.

Although the mortality rate is high among cases of embolectomy related to acute myocardial infarction, there is no significant difference in comparison to cases of embolectomy of other aetiology.

Among the twenty-eight patients who suffered acute myocardial infarction and underwent embolectomy, the mortality rate was $21.4 \%$. In the series of eighty-six cases with other aetiology, mortality was $18 \cdot 6 \%$.

Death of four patients within 10-17 days following embolectomy, indicates that they survived the surgical procedure, but succumbed to the basic underlying disease.

Grendahl (1967) who recorded 302 deaths among 1109 cases of acute myocardial infarction, found that during a period of 1 month $27 \%$ died. Seventy-one per cent of these died within the first 5 days following onset of the acute myocardial infarction. From the remaining $29 \%$ who survived the initial 5 days, $7.9 \%$ died. The present authors also found that $7 \%$ of those patients who survived the first week following onset of acute myocardial infarction died. The six elderly patients in their group who died (two with a history of myocardial infarction and three with diabetes mellitus) most likely represent the $7 \%$ mortality expected in cases surviving the first week following the onset of acute myocardial infarction.

\section{References}

FOGARTY, T.J. (1973) Complications of arterial embolectomy, chapter 4. In: Complications in Vascular Surgery (Ed. by H. G. Beebe), pp. 95-102. Lippincott Company.

Gould, L. \& Migliorelli, F. (1967) Aortic saddle embolus in acute myocardial infarction. American Journal of Cardiology, 19, 231.

GrendahL, H. (1967) Early death in acute myocardial infarction. A retrospective study of 302 cases. Acta medica scandinavica, 181, 655 .

NielSen, B.L. \& Sorensen, H.R. (1968) The operative treatment of emboli in the extremities of patients in the acute coronary occlusion. Danish Medical Bulletin, 15, 249.

Stallone, R.J., Blaisdell, F.W., Cafferata, H.T. \& Levin, S.M. (1969) Analysis of morbidity and mortality from arterial embolectomy. Surgery, 65, 207.

Stavorovsky, M. (1971) Problems in the treatment of arterial embolism. Harefuah, 80, 305.

Thompson, J.E., Sigler, L., Raut, P.S., Austin, D.J. \& Patman, R.D. (1970a) Arterial embolectomy; a 20 year experience with 163 cases. Surgery, 67, 212.

Thompson, J.E., Weston, A.S., Sigler, L., Raut, P.S., Austin, D.J. \& Patman, R.D. (1970b) Arterial embolectomy after acute myocardial infarction (a study of 31 patients). Annals of Surgery, 171, 979. 